\title{
Understanding Bubbly Episodes
}

\author{
By Vasco M. Carvalho, Alberto Martin and Jaume Ventura*
}

Wealth has fluctuated substantially in recent US macroeconomic history. Figure 1 documents this by plotting the evolution of real net worth of US households and non-profit organizations between 1950 and 2010. ${ }^{1}$ Up until the early 1990s the evolution of wealth seems relatively stable, displaying only mild and short-lived fluctuations around its trend. Since then, however, this behavior changed dramatically. From 1995 to 1999 , and again from 2002 to 2006, wealth grew at a staggering $9 \%$ per year only to contract violently in subsequent years.

The magnitude of these episodes is unprecedented in US post-war history. To grasp their significance it is useful to scale wealth by GDP. From 1950 to 1995, the wealth to GDP ratio had been stable around a value of 3.4. In the mid 1990s, wealth took off, peaking at 4.6 and 5 times GDP in 1999 and 2006 respectively. Both peaks were followed by destruction of wealth on a massive scale, bringing the wealth to GDP ratio close to its historical average by the end of the sample.

\footnotetext{
* CREI, UPF and Barcelona GSE. Carvalho acknowledges financial support from the Government of Catalonia (grant 2009SGR1157), the Spanish Ministry of Education and Science (grants Juan de la Cierva, JCI2009-04127, ECO2008-01665 and CSD2006-00016). Martin and Ventura acknowledge support from the Spanish Ministry of Economy and Competitivity (grant ECO2011-23192) and the Generalitat de CatalunyaAGAUR (grant 2009SGR1157). In addition, Ventura acknowledges support from the ERC (Advanced Grant FP7-249588), and Martin from the Spanish Ministry of Science and Innovation (grant Ramon y Cajal RYC-2009-04624). All authors thank the Barcelona GSE Research Network.

${ }^{1}$ Data on household and non-profit net worth for the US was obtained from the Flow of Funds at the Federal Reserve. We have deflated it by the CPI. The net worth series tracks the evolution of household assets and liabilities over time valued at market prices. To the extent that households are directly or indirectly the ultimate owners of the economy's entire capital stock and land, this series thus reflects the evolution of the market value of these productive assets over time. In reality, though, US households own some capital and land abroad and part of the US capital stock and land is in turn owned by foreigners. To account for this, we substract throughout the US net foreign asset position from the net worth series.
}

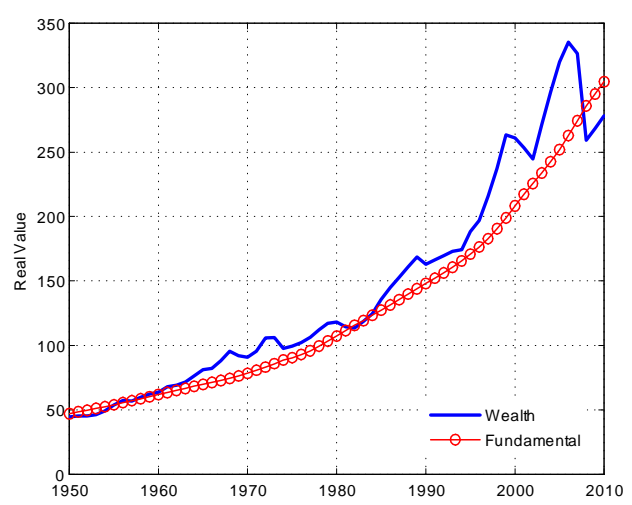

Figure 1: Real value of U.S. wealth and its fundamental, 1960:2010.

The recent recession has painfully exposed that these sharp movements in wealth are associated with fluctuations in other macroeconomic variables. Indeed, over the last two decades, the growth rates of consumption, output and the capital stock have moved in tandem with the growth rate of the wealth to GDP ratio, with peak correlations of $0.83,0.88$ and 0.82 respectively. Interestingly, these peak correlations correspond to the correlation of each of these variables with the one-year lagged growth rate of wealth, suggesting that movements in wealth tend to lead fluctuations in other variables. ${ }^{2}$

How can we explain these fluctuations in wealth? Why are these fluctuations associated with sharp changes in consumption, output and the capital stock? In Alberto Martin and Jaume Ventura (2011, forthcoming) and Vasco M. Carvalho, Alberto Martin and Jaume Ventura (2012) we address these questions by developing a model that features two main building blocks: rational bubbles and financial frictions. In this short paper, we explain why each of these building blocks is crucial to explain the evidence reported above.

\footnotetext{
${ }^{2}$ All correlations reported are significant at the 5\% level. Data for GDP, consumption and investment was sourced from the Penn World Tables. The capital stock series was then constructed from the investment data by applying the perpetual inventory method.
} 


\section{Rational bubbles}

The theory of rational bubbles shows that asset prices can be interpreted as the sum of two components: the fundamental and the bubble. Consider, for instance, the value of all productive assets located in the US, which mostly consist of its capital stock and land. Let $W_{t}$ be this value in period $t$; and let $r_{t+1}$ be the expected return that the market requires for holding them. Then, it follows that:

$$
\begin{aligned}
& \left(1+r_{t+1}\right) \cdot W_{t} \\
& =E_{t}\left\{D_{t+1}+\left(W_{t+1}-I_{t+1}-N_{t+1}\right)\right\}
\end{aligned}
$$

where $I_{t+1}$ and $N_{t+1}$ are the value of additions to the stocks of productive assets and bubbles in period $t+1$; and $E_{t}\{\cdot\}$ is the expectation operator. Equation (1) simply says that the expected return of holding US productive assets from pe$\operatorname{riod} t$ to period $t+1$ is $\left(1+r_{t+1}\right) \cdot W_{t}$. This expected return in period $t+1$ consists of the income generated by these assets, i.e. $D_{t+1}$; plus their residual value in period $t+1$, i.e. $W_{t+1}-I_{t+1}-N_{t+1}$.

Iterating Equation (1) forward, we find that

$$
W_{t}=F_{t}+B_{t} \text {, }
$$

where $F_{t}$ and $B_{t}$ are the fundamental and the bubble:

$$
\begin{aligned}
F_{t} & \equiv E_{t}\left\{\sum_{\tau=1}^{\infty} \frac{D_{t+\tau+1}-I_{t+\tau+1}}{\prod_{i=1}^{\tau}\left(1+r_{t+i}\right)}\right\} \\
B_{t} & \equiv E_{t}\left\{\lim _{\tau \rightarrow \infty} \frac{W_{t+\tau+1}}{\prod_{i=1}^{\tau}\left(1+r_{t+i}\right)}\right\} \\
& -E_{t}\left\{\sum_{\tau=1}^{\infty} \frac{N_{t+\tau+1}}{\prod_{i=1}^{\tau}\left(1+r_{t+i}\right)}\right\}
\end{aligned}
$$

The fundamental is the present discounted value of all the cash-flows that the productive assets located in the US in period $t$ might generate in the future. The bubble is the value of all pyramid schemes attached to US productive assets. Note that the bubble can be further divided in two terms. The first one, which is positive, is the expected value of all bubbles that have ever started and will ever start. The second term, which is negative, is the expected value of bubbles that have not started yet. ${ }^{3}$

According to the theory, thus, bubbles are nothing but pyramid schemes. In these schemes, contributions are voluntary and entitle the contributor to receive next period's contribution. Starting a pyramid scheme yields a windfall to the first participant, which consists of the first contribution to the scheme. Later participants in the scheme effectively purchase the right to the next contribution with their own contribution. A key feature of bubbles is that they do not constitute a promise by the seller to deliver future payments. Thus, they might be traded even in situations in which borrowing is not possible or severely restricted.

At first sight, this concept of a bubble as a pyramid scheme might seem quite abstract or exotic. But it is fairly easy to find real-world situations that correspond fairly well to this concept. Consider, for instance, the stock of a firm that is traded at a price that exceeds its fundamental, i.e. the net present value of the dividends that this stock will generate. This "overvalued" price might be part of an equilibrium if buyers rationally expect to sell these stocks in the future at a price that also exceeds the fundamental. Consider, alternatively, credit given to a firm in excess of the net present value of the cash-flows that this firm will generate. This "excessive" credit might be part of an equilibrium if creditors rationally expect that the firm will be able to raise enough credit in the future to repay them.

Overvalued stock prices and excessive credit can be therefore be interpreted as bubbles, that is, as voluntary contributions to the firm's financing that give the right to the next voluntary contribution. Once we think in these terms, the concept of a bubble ceases to be abstract or exotic and it becomes quite mundane. Indeed, it seems to capture the type of real-world behavior that our macroeconomic models should be generating as an equilibrium phenomenon.

Still, standard macroeconomic models largely ignore the possibility of bubbles and try to explain all fluctuations in wealth as a result of fluc-

\footnotetext{
${ }^{3}$ Interestingly, the possibility of bubbles implies that the value of an asset might differ from that of a portfolio that replicates the cash-flows that this asset will generate. This portfolio would only be worth the fundamental. This observation has important implications for the ability of financial markets to perform arbitrage.
} 
tuations in the fundamental. We show the limitations of this approach by performing a simple calculation of this fundamental. To do this, we measure the cash-flows that US productive assets generate as capital income, net of taxes and investment. ${ }^{4}$ We then compute the expected present discounted value of these cash-flows by following Robert J. Shiller (2005) in making two assumptions: (i) the expected return, $r_{t+i}$, is constant for all time horizons $i$, and well approximated by the average real return on wealth over the 1950-2010 period; and (ii) out-of-sample cash-flows grow at a constant rate - given by the historical average of their real growth rate - and we resort to perfect foresight for withinsample cash-flows. This procedure generates an estimate of the fundamental that is plotted as the circled line in Figure 1.

Two facts are immediately apparent from Figure 1. First, up until the early 1990s - and despite the crudeness of the method described above - wealth has remained remarkably close to its fundamental. While we do observe deviations from the fundamental during this period, these are typically mild and short-lived. Second, the two boom-and-bust episodes of the last two decades constitute unprecedented deviations from the fundamental. This is consistent with the popular view that the evolution of wealth since the late 1990s has been in part driven by the appearance and subsequent bursting of bubbles in markets for key assets such as equity and real estate. ${ }^{5}$

This poses a challenge to macroeconomics. To understand recent developments in the US and other industrial countries, we need to introduce bubbly episodes into the general equilibrium models that are routinely used in modern macroeconomics. Only then could these models

\footnotetext{
${ }^{4}$ We first compute the labor share as (Employee Compensation) / (GDP- Indirect Taxes) from the NIPA tables and then multiply one minus the labor share by GDP to obtain aggregate capital income. We then compute aggregate capital taxes by applying the methodology in Enrique Mendoza, Assaf Razin and Linda Tesar (1994) to OECD tax revenue data. This yields an effective capital tax rate from 1970 to 2010 . For the period before 1970 we assume that the effective capital tax rate is given by its 1970-2010 average. Finally, we take gross private domestic investment from the NIPA tables.

${ }^{5}$ Naturally, the two assumptions made to compute the fundamental are crude. But we have experimented with a variety of alternative assumptions and they all lead to the same conclusion: it is difficult to explain the recent evolution of aggregate wealth through fluctuations in fundamental values.
}

be used to determine when bubbly episodes can occur, to study their macroeconomic effects, and to derive policy implications on how to handle them.

This challenge is not new, however. Paul Samuelson (1958) started the theory of rational bubbles by showing that, under certain conditions, useless assets are valued in competitive equilibria and this raises consumption and welfare. Jean Tirole (1985) was the first to interpret Samuelson's useless assets as bubbles. Building on Peter Diamond's (1965) neoclassical growth model, Tirole showed that bubbles can only exist if the economy is dynamically inefficient. In this case, bubbles absorb part of the economy's savings, crowding out inefficient investment and reducing the capital stock and output. This liberates resources that can be used to raise consumption and welfare.

The theoretical relevance of the SamuelsonTirole model is undeniable. But its practical relevance is limited when we confront recent macroeconomic events. In the bubbly episodes described above, consumption increased (and welfare seemed high!). But bubbles did not crowd out investment and reduce the capital stock and output as predicted. Indeed, just the opposite happened. Even worse, the SamuelsonTirole model predicts that these bubbly episodes could not have occurred in the first place. Recall that the theory predicts that bubbles can only arise if the economy is dynamically inefficient. Abel et al. (1989) showed that, in the Samuelson-Tirole model, dynamic inefficiency requires that capital income exceed gross investment, i.e. $D_{t}-I_{t}<0$. This is not the case in the US, Japan or any other industrial country that has experienced a bubbly episode recently.

Why does the Samuelson-Tirole model fail to account for these bubbly episodes? The answer turns out to be quite simple: it ignores financial frictions. Martin and Ventura (2011, forthcoming) and Carvalho, Martin and Ventura (2012) show that, in the presence of financial frictions, bubbles crowd out inefficient investments and liberate resources that can be used both to raise consumption and to increase efficient investments. By improving the workings of the financial system, bubbles can therefore lead to increases in the capital stock and output. Moreover, the presence of financial frictions substantially relaxes the conditions for the 
existence of bubbly episodes. In particular, these episodes are possible even if the economy is dynamically efficient and $D_{t}-I_{t}>0$. We explain how this works next.

\section{Financial frictions}

There is a long tradition in macroeconomics of models that show the importance of wealth in overcoming financial frictions. ${ }^{6}$ Not surprisingly then, bubbles that raise wealth should also relax credit constraints and alleviate the effects of financial frictions. We show this with the help of two simple examples. ${ }^{7}$

Consider a risk-neutral entrepreneur that is deciding whether or not to invest in a project. The project requires an investment of $I$ in period 0 and it yields a deterministic stream of cash flows $C_{t}$. Letting $r$ denote the constant market interest rate, assume that $\sum_{\tau=1}^{\infty} C_{\tau} /(1+r)^{\tau}>$ $I$, so that the present discounted value of the project's cash flows exceeds the required investment. The entrepreneur's wealth equals $S<I$, so that he needs to raise funds to undertake the project. If financial markets were frictionless, the project would be undertaken.

But financial markets are not frictionless in the real world. Imagine, for instance, that only an amount $\hat{C}_{t}<C_{t}$ of the cash-flows generated by the project are verifiable by third parties, so that any contract requiring the entrepreneur to repay more than $\hat{C}_{t}$ cannot be enforced. Assume further that the present discounted value of these repayments falls short of the financing needed, i.e. $\sum_{\tau=1}^{\infty} \hat{C}_{\tau} /(1+r)^{\tau}<I-S$. Does this mean that the project will not be undertaken? Not necessarily.

Let $V_{t}$ be the amount of financing that the entrepreneur can obtain from creditors at time $t$. Under our assumptions, we have that:

$$
V_{t} \leq \frac{1}{1+r} \cdot\left[\hat{C}_{t+1}+V_{t+1}\right]
$$

\footnotetext{
${ }^{6}$ The seminal papers are Bernanke and Gertler [1989] and Kiyotaki and Moore [1997].

${ }^{7}$ Another channel through which bubbles can transfer resources from inefficient to efficient investors is the cost of capital. As the bubble eliminates inefficient investments, the cost of capital declines and this raises efficient investments. See Ventura [forthcoming].
}

Iterating forward Equation (2), we can write

$$
V_{0} \leq \hat{F}_{0}+B_{0}
$$

where $\hat{F}_{0}$ and $B_{0}$ are defined as:

$$
\begin{aligned}
\hat{F}_{0} & \equiv \sum_{\tau=1}^{\infty} \frac{\hat{C}_{\tau}}{(1+r)^{\tau}} \\
B_{0} & \equiv \lim _{\tau \rightarrow \infty} \frac{V_{\tau}}{\prod_{i=1}^{\tau}(1+r)}
\end{aligned}
$$

Equation (3) contains the core of our argument. It says that the amount of financing that entrepreneurs can obtain from creditors at time $t$ is limited by two components. First, there is the fraction of the project's cash-flows or fundamental that can be promised to creditors, $\hat{F}_{0}$. Second, there is the project's bubble component, $B_{0}$. As we have explained before, we could think of the financing backed by the bubble as an "overvaluation" of equity or as "excessive" credit.

In this example, the bubble directly helps overcome contracting problems by providing additional wealth to the entrepreneur and allowing him to undertake additional investments. If, in addition, there are adverse selection problems, financial markets might redistribute this wealth effect in such a way that magnifies its impact on investment.

To see this, imagine that the entrepreneur's wealth now takes the form of an asset that must be sold in order to finance investment. In particular, some entrepreneurs have a "good" asset that yields a future payoff $S^{G}>I-\hat{F}_{0}$, while the rest have a "bad" asset that yields a future payoff $S^{B}<I-\hat{F}_{0}$. Let $S$ denote the average quality of all assets and assume that $S>I-\hat{F}_{0}$. If asset quality is observable, entrepreneurs with good assets invest whereas entrepreneurs with bad assets can only do so if they generate a bubble no smaller than $I-\hat{F}_{0}-S^{B}$.

But in real-world financial markets asset quality is not always observed. In this case, assets are traded at a single price that reflects the average quality in the market. If all entrepreneurs were to sell their assets, this price would be $S$ and everyone would raise enough resources to invest. But would they want to do so? Entrepreneurs with bad assets clearly would. Entrepreneurs with good assets, however, effectively lose $S^{G}-S$ by selling their asset. If the gain 
from investment does not compensate them for this loss, good assets will not be traded in the market. If they are not, adverse selection leads to a market shutdown and nobody invests.

In this case, bubbles not only raise wealth but also redistribute towards entrepreneurs with bad assets. The reason is that bubbles raise the returns to investment and therefore provide greater incentives for entrepreneurs to sell their good assets at a loss. If this effect is sufficiently large, bubbles sustain the equilibrium in which all assets are sold at price $S$ and all entrepreneurs invest.

These simple examples illustrate why fluctuations in investor sentiment have strong effects on the functioning of financial markets. When investors are optimistic, bubbles are created and financial markets are able to overcome their frictions. Banks extend loans today in the expectation that their customers will be able to borrow more in the future. Stock market investors purchase stocks at a high price today in the expectation that others will buy them at an even higher price in the future. This enhanced ability of financial markets to intermediate during a bubbly episode fosters capital accumulation and economic growth.

But investor sentiment is volatile and might change quickly. When investors turn pessimistic, the bubbly episode ends and intermediation sharply falls. Financial markets, which seemed efficient during the bubbly episode, are now plagued by contracting problems and adverse selection. Banks stop providing credit and stock prices collapse. This leads to a contraction in the capital stock and negative economic growth.

Financial frictions therefore raise the practical relevance of the theory by generating bubbly episodes that roughly resemble those that we have observed in recent times. But this would not be fully satisfactory if these episodes could only happen in economies where capital income falls short of gross investment, i.e. $D_{t}-I_{t} \leq 0$. As mentioned already, this condition, which in the Samuelson-Tirole model was essential for bubbly episodes to exist, is not satisfied in the US and other industrial countries.

Interestingly, Martin and Ventura (forthcoming) show that, in the presence of financial frictions, this condition is no longer relevant to assess whether bubbly episodes can exist. In a nutshell, the observation that capital income exceeds gross investment only says that the average investment in the economy is dynamically efficient. In the absence of financial frictions, returns are equalized across investments and this also implies that all investments are dynamically efficient. In the presence of financial frictions, however, high-return investments that are dynamically efficient might co-exist with low-return investments that are dynamically inefficient. Thus, the observation that the average investment is dynamically efficient does not rule out the possibility that the economy contains pockets of dynamically inefficient investments. It is precisely in this situation that bubbles are able to crowd out inefficient investments and liberate resources that can be used both to raise consumption and to increase efficient investments.

\section{Concluding remarks}

The theory proposed here has implications for the way we think about economic fluctuations. First, it lays the foundations for the introduction of investor sentiment shocks into standard macroeconomic models. We have argued here that this is important to explain the recent macroeconomic history of the US and other industrial countries. Second, it has important implications for the way we think about policy responses to downturns. If a downturn originates in a negative productivity shock that tightens credit constraints, the government might have little to do unless it has an advantage in lending vis-a-vis the private sector. But if a downturn originates in a negative investor sentiment shock that bursts a bubble, the government might have an important role to play in coordinating expectations and taking the economy back to the bubbly equilibrium.

\section{References}

Bernanke, B. and M. Gertler, 1989, Agency Costs, Net Worth and Business Fluctuations, American Economic Review 79, 14-31.

Carvalho, V.M., A. Martin and J. Ventura, 2012, Bubbly Business Cycles, CREi working paper. Kiyotaki, N., and J. Moore, 1997, Credit Cycles, Journal of Political Economy 105, 211-248.

Martin, A. and J. Ventura, 2011, Theoretical Notes on Bubbles and the Current Crisis, IMF 
Economic Review 59, 6-40.

Martin, A. and J. Ventura, forthcoming, Economic Growth with Bubbles, American Economic Review.

Mendoza, E., A. Razin, and L. Tesar, 1994, Effective Tax Rates in Macroeconomics: Crosscountry Estimates of Tax Rates on Factor Incomes and Consumption, Journal of Monetary Economics 34, 297-323.

Samuelson, P., 1958, An Exact Consumptionloan Model of Interest with or without the Social Contrivance of Money, Journal of Political Economy 66, 467-482.

Shiller, R. Irrational Exuberance, Princeton University Press 2005.

Tirole, J., 1985, Asset Bubbles and Overlapping Generations, Econometrica 53 (6), 1499-1528.

Ventura, J., forthcoming, Bubbles and Capital Flows, Journal of Economic Theory. 